\title{
On the benefits of semi-active suspensions with inerters
}

\author{
Xin-Jie Zhang ${ }^{\mathrm{a}, \mathrm{b}}$, Mehdi Ahmadian ${ }^{\mathrm{b}, *}$ and Kong-Hui Guo ${ }^{\mathrm{a}, *}$ \\ ${ }^{a}$ State Key Laboratory of Automotive Simulation and Control, Jilin University, Changchun, China \\ ${ }^{\mathrm{b}}$ Center for Vehicle Systems and Safety, Virginia Tech, Blacksburg, VA, USA
}

Received 31 July 2010

Revised 5 November 2010

\begin{abstract}
Inerters have become a hot topic in recent years especially in vehicle, train, building suspension systems, etc. Eight different layouts of suspensions were analyzed with a quarter-car model in this paper. Dimensionless root mean square (RMS) responses of the sprung mass vertical acceleration, the suspension travel, and the tire deflection are derived which were used to evaluate the performance of the quarter-car model. The behaviour of semi-active suspensions with inerters using Groundhook, Skyhook, and Hybrid control has been evaluated and compared to the performance of passive suspensions with inerters. Sensitivity analysis was applied to the development of a high performance semi-active suspension with an inerter. Numerical simulations indicate that a semi-active suspension with an inerter has much better performance than the passive suspension with an inerter, especially with the Hybrid control method, which has the best compromise between comfort and road holding quality.
\end{abstract}

Keywords: Inerter, groundhook, skyhook, hybrid, quarter-car, RMS

\section{Introduction}

Automotive suspensions are designed to provide many functions such as vibration isolation of the passenger compartment from road inputs and control vertical tire loads to optimize braking, acceleration and handling. Many papers have appeared in the literature on the optimization of passive suspensions, semi-active suspensions, and fully active suspensions. This interest in improved and optimized suspensions has become of great interest, not only to the academic community, but also to the auto manufacturers [1].

An inerter was proposed in [2], with a genuine two-terminal device equivalent to an electrical capacitor, which has been studied in vehicle, train, building suspension systems, etc. [2,5]. The relative acceleration between the terminals is proportional to the force applied at the terminals, i.e. $F=b \frac{d\left(V_{1}-V_{2}\right)}{d t}$, where $\mathrm{b}$ is the constant of proportionality in kilograms, called inertance. The admittance between two terminals is $Y(s)=b s$, where $s$ is the Laplace variable. It is like a flywheel that can be used to absorb and release kinetic energy. Some prototype inerters have been built [6, 8] and tested at the Cambridge University [9]. Linear Matrix Inequalities (LMI) and Bilinear Matrix Inequalities (BMI) have been used for optimizing a suspension's performance [10,11]. Improvements of about $10 \%$ or greater were shown for measures of ride, tire normal load and handling of a quarter-car with the inerter [12].

An inerter's nonlinear behaviour, including friction, backlash and the elastic effect was researched in $[13,14]$ and a test platform has been built to verify the nonlinear properties of the inerter model [14]. The performance benefits were slightly degraded by nonlinearities, but it is still better than the traditional passive suspension, especially when the suspension stiffness is large. A mechatronic suspension composed of a ball-screw inerter and permanent

\footnotetext{
*Corresponding authors: Mehdi Ahmadian, 3103 Commerce St, Blacksburg, VA, 24060, USA. Tel.: +1 540231 1408; E-mail: ahmadian@vt.edu; Kong-Hui Guo, State Key Laboratory of Automobile Dynamics Simulation, Jilin University, China; 5988 Renmin St, Changchun, Jilin Prov., 130025, China. Tel.: +86 4318509 5090; E-mail: guokonghui@gmail.com.
} 


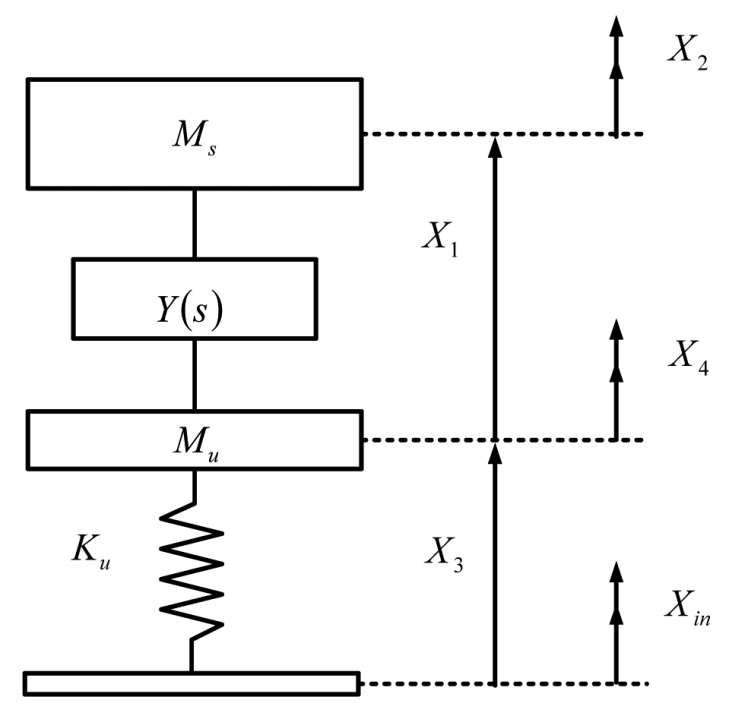

Fig. 1. A quarter-car model with a Passive suspension.

magnet electric machine is achieved through the combination of mechanical and electrical networks. The high-order transfer functions from LMI approaches can be easily realized by electrical circuits which can significantly improve the performance, especially for soft systems where the traditional inerter structures cannot achieve significant performance improvement [15].

Groundhook, Skyhook and Hybrid control are semi-active control schemes that can be effectively applied to automobile suspensions. The Skyhook configuration has a damper connected to some inertial reference in the sky. The Groundhook model differs from the Skyhook model in that the damper is connected to the unsprung mass instead of sprung mass. The Hybrid policy takes the advantage of the benefits of both Skyhook and Groundhook control [16].

In this paper, eight different layouts of suspension are analyzed with a quarter-car model. The dimensionless root mean square response of the sprung mass vertical acceleration, the suspension travel and the tire deflection are derived to evaluate the performance of the quarter-car model. Sensitivity analysis will be applied to the development of high performance semi-active suspension with an inerter. The effects of dimensionless parameters are considered and the performance of a passive suspension with an inerter and a semi-active suspension with an inerter are compared in order to highlight the benefits of a semi-active suspension with an inerter.

\section{System model}

A quarter-car model with passive suspension is shown in Fig. 1 and another model with semi-active suspension is shown in Fig. 2. Each model consists of a single sprung mass, $M_{s}$, free to move in the vertical direction, connected to an unsprung mass, $M_{u}$, free to move vertically with respect to the sprung mass. The tire is modelled as a spring of vertical stiffness, $k_{u}$, and the tire damping is neglected. The Laplace transform, $Y(s)$, is the admittance between the sprung mass and the unsprung mass. A linear damper with a damping rate of $\alpha\left(C_{o n}-C_{o f f}\right)$ connects the sprung mass to some inertial reference in the sky and a linear damper with a damping rate of $(1-\alpha)\left(C_{\text {on }}-C_{\text {off }}\right)$ connects the unsprung mass to some inertial reference in the sky, as shown in Fig. 2. When $\alpha$ is 1 , the control policy reduces to pure Skyhook, whereas when $\alpha$ is 0 , the control is purely Groundhook. Otherwise it will be a Hybrid control. The states of the model are defined as:

The deflection of the suspension $\left(X_{1}\right)$

The velocity of the sprung mass $\left(X_{2}\right)$

The deflection of the tire $\left(X_{3}\right)$

The velocity of the unsprung mass $\left(X_{4}\right)$ 


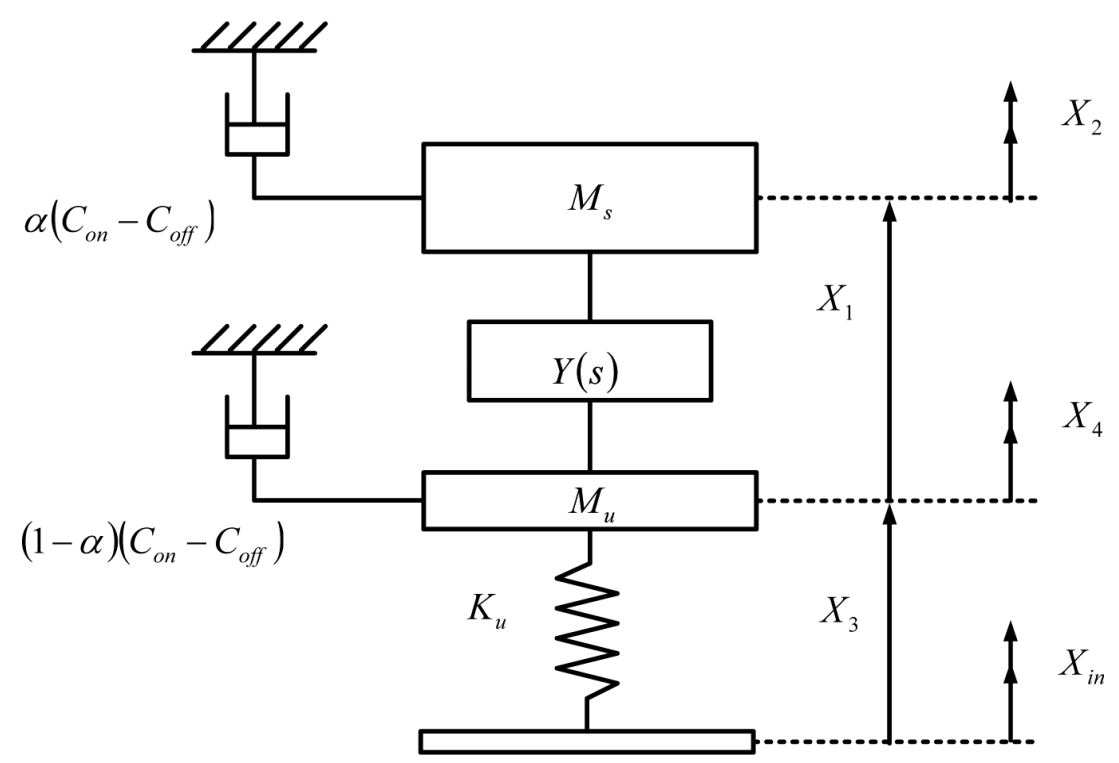

Fig. 2. A quarter-car model with a semi-active suspension.

The state-space system of the passive suspension of Fig. 1 is Eqs (1) and (2) is the state-space system of the semi-active suspension of Fig. 2. Transforming to Laplace domain results in Eqs (3) and (4).

$$
\begin{aligned}
& {\left[\begin{array}{c}
\dot{X}_{1} \\
\dot{X}_{2} \\
\dot{X}_{3} \\
\dot{X}_{4}
\end{array}\right]=\left[\begin{array}{cccc}
0 & 1 & 0 & -1 \\
0 & -\frac{Y}{M_{s}} & 0 & \frac{Y}{M_{s}} \\
0 & 0 & 0 & 1 \\
0 & \frac{Y}{M_{u}} & \frac{-k_{u}}{M_{u}} & -\frac{Y}{M_{u}}
\end{array}\right]\left[\begin{array}{c}
X_{1} \\
X_{2} \\
X_{3} \\
X_{4}
\end{array}\right]+\left[\begin{array}{c}
0 \\
0 \\
-1 \\
0
\end{array}\right] V_{i n}} \\
& {\left[\begin{array}{c}
\dot{X}_{1} \\
\dot{X}_{2} \\
\dot{X}_{3} \\
\dot{X}_{4}
\end{array}\right]=\left[\begin{array}{cccc}
0 & 1 & 0 & -1 \\
0-\frac{Y+\alpha\left(C_{o n}-C_{o f f}\right)}{M_{s}} & 0 & \frac{Y}{M_{s}} \\
0 & 0 & 0 & 1 \\
0 & \frac{Y}{M_{u}} & \frac{-k_{u}}{M_{u}}-\frac{Y+(1-\alpha)\left(C_{o n}-C_{o f f}\right)}{M_{u}}
\end{array}\right]\left[\begin{array}{c}
X_{1} \\
X_{2} \\
X_{3} \\
X_{4}
\end{array}\right]+\left[\begin{array}{c}
0 \\
0 \\
-1 \\
0
\end{array}\right] V_{i n}} \\
& {\left[\begin{array}{cccc}
s & -1 & 0 & 1 \\
0 s+\frac{Y(s)}{M_{s}} & 0 & -\frac{Y(s)}{M_{s}} \\
0 & 0 & s & -1 \\
0 & -\frac{Y(s)}{M_{u}} & \frac{k_{u}}{M_{u}} & s+\frac{Y(s)}{M_{u}}
\end{array}\right]\left[\begin{array}{c}
X_{1} \\
X_{2} \\
X_{3} \\
X_{4}
\end{array}\right]=\left[\begin{array}{c}
0 \\
0 \\
-1 \\
0
\end{array}\right] V_{i n}} \\
& {\left[\begin{array}{lccc}
s & -1 & 0 & 1 \\
0 s+\frac{Y(s)+\alpha\left(C_{o n}-C_{o f f}\right)}{M_{s}} & 0 & -\frac{Y(s)}{M_{s}} \\
0 & 0 & s & -1 \\
0 & -\frac{Y(s)}{M_{u}} & \frac{k_{u}}{M_{u}} s+\frac{Y(s)+(1-\alpha)\left(C_{o n}-C_{o f f}\right)}{M_{u}}
\end{array}\right]\left[\begin{array}{c}
X_{1} \\
X_{2} \\
X_{3} \\
X_{4}
\end{array}\right]=\left[\begin{array}{c}
0 \\
0 \\
-1 \\
0
\end{array}\right] V_{\text {in }}}
\end{aligned}
$$

Eight different layouts as candidate suspension struts are listed in Fig. 3. Layout s3 and Layout s4 show a conventional parallel spring-damper augmented by an inerter in parallel or in series with the damper. Layout s5 is a pair of centering springs $k_{1}$ in parallel with the damper and the inerter from Layout $\mathrm{s} 4$. The centering spring may be preloaded against the damper and the inerter. Layout s6 is similar but allows for unequal springs $k_{1}$ and $k_{2}$. There is an additional relaxation spring $k_{b}$ in Layout s7 and s8. Layout $\mathrm{s} 9$ has a centering spring $k_{1}$ paralleled with the damper from Layout s4 and Layout s10 includes a relaxation spring $k_{b}$ in series with the damper from Layout s4.

The admittance of each layout is shown in the Table $1 . C_{s}$ will be changed to $C_{\text {off }}$ when it is used in the semi-active suspension with an inerter. The transfer function is solved using MATLAB. 
K

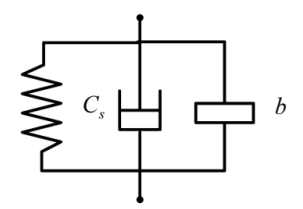

(a) Layout s3

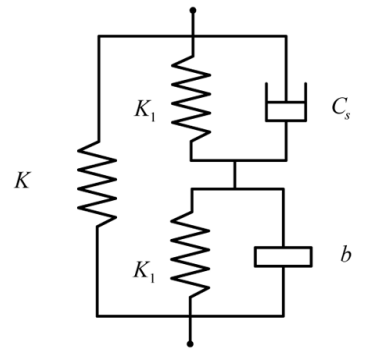

(c) Layout s5

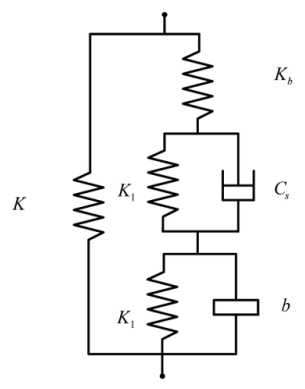

(e) Layout s7

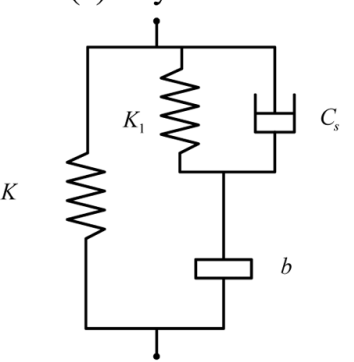

(g) Layout s9
K

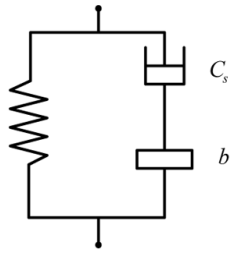

(b) Layout s4

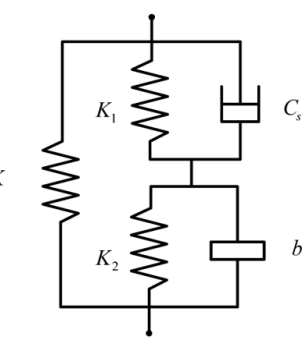

(d) Layout s6

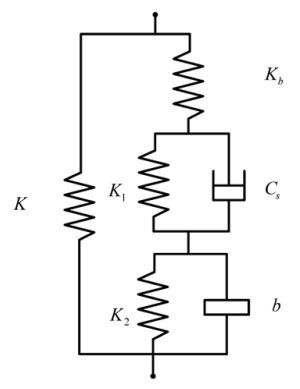

(f) Layout s8

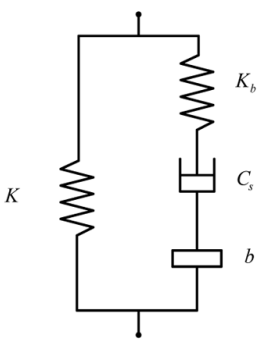

(h) Layout s10

Fig. 3. The eight suspension layouts.

\section{Performance evaluation}

Usually, there is a compromise in suspension design between passenger comfort, handling, tire vertical loads, and limits of suspension travel. All previously mentioned layouts are analyzed for their performance. The motion variables of interest in this analysis are: the sprung mass vertical acceleration $\dot{X}_{2}$, the suspension deflection $X_{1}$, and the tire deflection $X_{3}$. The mean square response of any motion variable ' $y$ ' can be computed using the relationship:

$$
E\left[Y^{2}\right]=S_{0} \int_{-\infty}^{\infty}\left|H_{Y}(j \omega)\right|^{2} d \omega
$$


Table 1

Admittance of each layout

\begin{tabular}{|c|c|}
\hline $\begin{array}{l}S_{3}=\frac{k}{s}+c_{s}+b s \\
\quad \text { (a) Layout s3 }\end{array}$ & $\begin{array}{l}S_{4}=\frac{k}{s}+\frac{1}{\frac{1}{b s}+\frac{1}{c_{s}}} \\
\text { (b) Layout } \mathrm{s} 4\end{array}$ \\
\hline $\begin{array}{c}S_{5}=\frac{k}{s}+\frac{1}{\frac{1}{b s+\frac{k_{1}}{s}}+\frac{1}{c_{s}+\frac{k_{1}}{s}}} \\
\text { (c) Layout s5 }\end{array}$ & $\begin{aligned} S_{6}= & \frac{k}{s}+\frac{1}{\frac{1}{b s+\frac{k_{2}}{s}}+\frac{1}{c_{s}+\frac{k_{1}}{s}}} \\
& \text { (d) Layout s6 }\end{aligned}$ \\
\hline $\begin{array}{c}S_{7}=\frac{k}{s}+\frac{1}{\frac{1}{b s+\frac{k_{1}}{s}}+\frac{1}{c+\frac{k_{1}}{s}}+\frac{s}{k_{b}}} \\
\text { (e) Layout s7 }\end{array}$ & $\begin{array}{c}S_{8}=\frac{k}{s}+\frac{1}{\frac{1}{b s+\frac{k_{2}}{s}}+\frac{1}{c+\frac{k_{1}}{s}}+\frac{s}{k_{b}}} \\
\text { (f) Layout s8 }\end{array}$ \\
\hline $\begin{aligned} S_{9}= & \frac{k}{s}+\frac{1}{\frac{1}{b s}+\frac{1}{c_{s}+\frac{k_{1}}{s}}} \\
& (\mathrm{~g}) \text { Layout } \mathrm{s} 9\end{aligned}$ & $\begin{array}{l}S_{10}=\frac{k}{s}+\frac{1}{\frac{1}{b s}+\frac{1}{c}+\frac{s}{k_{b}}} \\
\text { (h) Layout s10 }\end{array}$ \\
\hline
\end{tabular}

$S_{0}$ is the spectral density of the input white-noise. $H_{y}(j \omega)$ is the transfer function relating the response variable ' $y$ ' to the white-noise input [17]. A standard H2-norm is $\|f(\mathrm{j} \omega)\|_{2}=\left(\frac{1}{2 \pi} \int_{-\infty}^{\infty}|f(j \omega)|^{2} d \omega\right)^{\frac{1}{2}}$, and the mean square response of motion variable ' $y$ ' can be written as

$$
E\left[Y^{2}\right]=2 \pi S_{0}\left(\left\|H_{y}(\mathrm{j} \omega)\right\|_{2}\right)^{2}
$$

The mean square responses of the sprung mass vertical acceleration, the suspension deflection and the tire deflection can be obtained as,

$$
\begin{aligned}
& E\left[\dot{X}_{2}^{2}\right]=2 \pi S_{0}\left(\left\|H_{\dot{X}_{2}}(\mathrm{j} \omega)\right\|_{2}\right)^{2} \\
& E\left[X_{1}^{2}\right]=2 \pi S_{0}\left(\left\|H_{X_{1}}(\mathrm{j} \omega)\right\|_{2}\right)^{2} \\
& E\left[X_{3}^{2}\right]=2 \pi S_{0}\left(\left\|H_{X_{3}}(\mathrm{j} \omega)\right\|_{2}\right)^{2}
\end{aligned}
$$

Dimensionless parameters can provide better insight into how the three mean square responses are influenced by vehicle model parameters [18]. The dimensionless expressions for the RMS of the sprung mass vertical acceleration, the RMS of the suspension deflection, and the RMS of the tire deflection can be derived as,

$$
\begin{aligned}
& \left(\frac{E\left[\dot{X}_{2}^{2}\right]}{\pi S_{0} \omega_{u}^{3}}\right)^{\frac{1}{2}}=\frac{\sqrt{2}\left(\left\|H_{\dot{X}_{2}}\right\|_{2}\right)}{\omega_{u}^{\frac{3}{2}}} \\
& \left(\frac{E\left[X_{1}^{2}\right]}{\pi S_{0}} \omega_{u}\right)^{\frac{1}{2}}=\sqrt{2}\left(\left\|H_{X_{1}}\right\|_{2}\right) \omega_{u}^{\frac{1}{2}} \\
& \left(\frac{E\left[X_{3}^{2}\right]}{\pi S_{0}} \omega_{u}\right)^{\frac{1}{2}}=\sqrt{2}\left(\left\|H_{X_{3}}\right\|_{2}\right) \omega_{u}^{\frac{1}{2}}
\end{aligned}
$$

where, $\omega_{u}$ is the natural frequency of the unsprung mass

$$
\omega_{u}=\sqrt{\frac{k_{u}}{M_{u}}}
$$

Equation (10) will be used for evaluating the vibration level, Eq. (11) will be used for evaluating the rattlespace requirement, and Eq. (12) will be used for evaluating the road-holding quality. 
Table 2

Model parameters

\begin{tabular}{lc}
\hline Parameter & Value \\
\hline Sprung Mass $M_{s}$ & $240 \mathrm{Kg}$ \\
Unsprung Mass $M_{u}$ & $36 \mathrm{Kg}$ \\
Primary spring stiffness $k$ & $16000 \mathrm{~N} / \mathrm{m}$ \\
Tire Vertical Stiffness $k_{u}$ & $160000 \mathrm{~N} / \mathrm{m}$ \\
Damping $C_{s}$ & $3920 \mathrm{Ns} / \mathrm{m}\left(\right.$ when $\left.\xi_{s}=1\right)$ \\
Corresponding Ratio $\xi_{s}$ & $0.05,0.16,0.26,0.37,0.480 .58,0.68,0.79,0.89,1.0$ \\
Semi-active damping coefficients $C_{o n}, C_{o f f}$ & $C_{o n}=2.2 C_{s}, C_{o f f}=0.2 C_{s}$ \\
Relaxation Spring Stiffness $k_{b}$ & $k_{b}=4 k$ \\
Centering Spring Stiffness $k_{1}$ & $k_{1}=0.4 k$ \\
Centering Spring Stiffness $k_{2}$ & $k_{2}=0.15 k$ \\
Equivalent Inertance ' $b$ ' & $150 \mathrm{Kg}$ \\
\hline
\end{tabular}

\section{Parameters}

This simulation considers eight different inerter layouts, combined with passive suspensions and semi-active suspensions. The parameters of the suspension systems are shown in Table 2. Sprung mass, unsprung mass and tire vertical stiffness are from [18] and were constant during the whole study. The value of other parameters in Table 2 is from a parametric study and sensitivity analysis, which is explained in next section.

\section{Parameters study and sensitivity analysis}

The parameters of passive suspensions with Layout $\mathrm{s} 3$ to Layout s7 were optimized in [12] and parameters of passive suspensions with Layout s9 and Layout s10 were optimized in [11]. Performance of these and other passive suspensions with inerters and semi-active suspensions with inerters were compared with each other, but the figures only show the results of Layout s8. This layout contains two different centering springs and a relaxation spring, which is suitable for being a benchmark.

\subsection{Effect of primary spring stiffness and damping}

The dimensionless stiffness ratio of a primary spring stiffness is

$$
r_{k}=\frac{k_{u}}{k}
$$

$r_{k}$ varies from 5 to 20 during the simulation and the damping value was changed from $196 \mathrm{Ns} / \mathrm{m}$ to $3920 \mathrm{Ns} / \mathrm{m}$. In this study, the tire vertical stiffness, $k_{u}$, is a constant and the primary spring stiffness, ' $k$ ', is variable because the tire vertical static stiffness is usually unchanged. All other parameters are listed in Table 2. Figure 4 shows the influence of damping and primary spring stiffness on the relationship between vibration isolation and suspension travel, using the dimensionless expressions shown in Eqs (10) and (11). There are three solid markers on each line in Fig. 4 through Fig. 13, which are used to mark the direction of increased damping. The largest solid markers are used to show the initial damping ratio of 0.05 for each simulation, the smallest solid markers show where the damping ratio is 1 . Another solid marker is used to show the damping ratio of 0.26 . Figure 4 shows that for the passive suspension with Layout $\mathrm{s} 8$, increasing the damping from a low value to a midrange value, results in both a lower RMS suspension travel and in a lower RMS vertical acceleration, but this trend is reversed as damping values increase.

For the semi-active suspension with Layout s8, Fig. 4 shows that increasing the damping always results in a lower RMS vertical acceleration for the Groundhook (b) and Hybrid (c) configurations. For the Skyhook (d) configuration, increasing the damping always results in a lower RMS vertical acceleration for stiffly sprung suspensions, but for lightly sprung suspensions, increasing the damping when the damping ratio is already high results in a higher RMS vertical acceleration. Figure 4 also shows that increasing the damping always results in a lower RMS suspension deflection for the Groundhook configuration. For the Skyhook and the Hybrid configurations, increasing the damping 


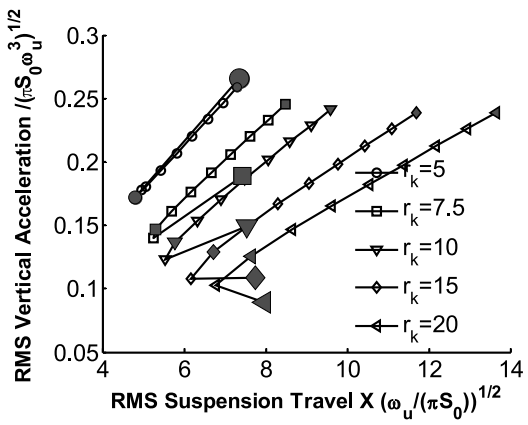

(a)

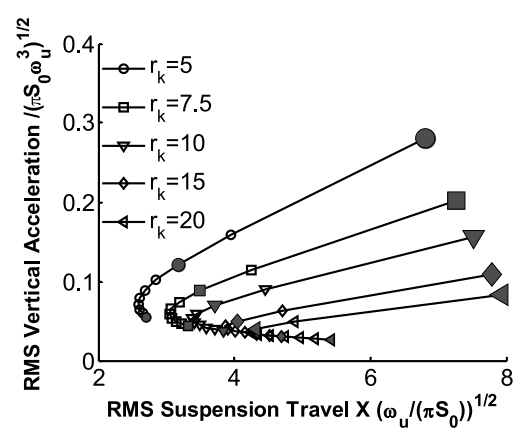

(c)

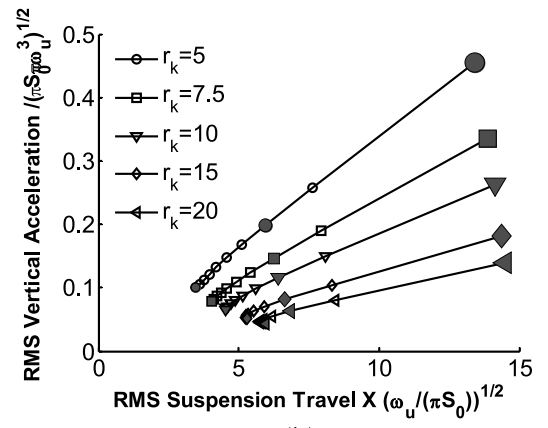

(b)

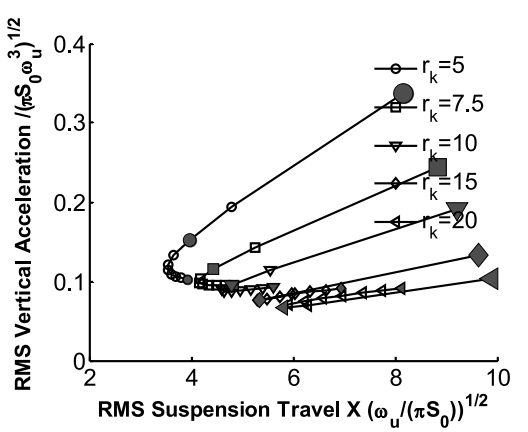

(d)

Fig. 4. Relationship between RMS acceleration and RMS suspension travel with layout s8 (effect of primary spring stiffness and damping): (a) Passive; (b) Groundhook; (c) Hybrid; (d) Skyhook.

from low values to midrange values results in a lower RMS suspension deflection. As damping values get high, this trend is reversed for the Skyhook configuration, and also for the Hybrid configuration as the damping gets even higher.

It should be noted that the Groundhook configuration is the one that always results in both a lower RMS vertical acceleration of the sprung mass and a lower RMS suspension displacement when the damping is increased. However, this performance comes at the cost of excessive sprung mass motion and the RMS vertical acceleration and suspension displacement that result from a lightly damped suspension can be high. The Hybrid configuration yields the best results for most of the stiffness and damping ratios when the objective is to minimize the RMS vertical acceleration and the RMS suspension displacement at the same time. Referring to Fig. 4, it yields points on the bottom left hand corner. In this regard, Skyhook control can be ranked as the second "best", among considered control policies when comparing vertical acceleration and suspension travel.

Figure 5 shows the relationship between the RMS vertical acceleration and the RMS tire deflection, using the dimensionless expressions shown in Eqs (10) and (12). Figure 5 shows the influence of damping on the RMS tire deflection for the Skyhook configuration: increasing the damping decreases the RMS tire deflection. The influence of damping on the RMS tire deflection follows a similar pattern for the passive, Groundhook and Hybrid configurations. Increasing the damping results in a lower RMS tire deflection until a certain value is reached; then the RMS tire deflection increases with the damping. The Groundhook and the Skyhook policies would not be used for high damping ratios: the Groundhook configuration yields very high accelerations, and the Skyhook configuration does not decrease acceleration as much as Hybrid control. Using the Hybrid configuration will therefore result in a better compromise between comfort and road holding quality.

Figures 4 and 5 show the dimensionless RMS of sprung mass vertical acceleration, suspension travel, and tire deflection of passive suspension with Layout s8 are $0.137,5.781$, and 1.953 when damping ratio is $0.26, r_{k}$ is 10 and other parameters are as listed in Table 2. Compared with passive suspension, the dimensionless RMS of sprung mass vertical acceleration with Groundhook decreased 15\%, the RMS of suspension travel increased 11\%, and the RMS of tire deflection decreased $20 \%$, because the Groundhook control performs just as well at isolating 
Table 3

Dimensionless RMS vertical acceleration

\begin{tabular}{llcccccccc}
\hline \multicolumn{2}{c}{ Layout } & S3 & S4 & S5 & S6 & S7 & S8 & S9 & S10 \\
\hline Passive & RMS ACC & 0.476 & 0.114 & 0.238 & 0.118 & 0.243 & $\mathbf{0 . 1 3 7}$ & 0.111 & 0.132 \\
& $\%$ & $100 \%$ & $100 \%$ & $100 \%$ & $100 \%$ & $100 \%$ & $\mathbf{1 0 0 \%}$ & $100 \%$ & $100 \%$ \\
Groundhook & RMS ACC & 0.216 & 0.128 & 0.213 & 0.109 & 0.211 & $\mathbf{0 . 1 1 6}$ & 0.112 & 0.129 \\
& $\%$ & $45 \%$ & $113 \%$ & $90 \%$ & $92 \%$ & $87 \%$ & $\mathbf{8 5 \%}$ & $101 \%$ & $98 \%$ \\
\multirow{3}{*}{ Hybrid } & RMS ACC & 0.269 & 0.055 & 0.068 & 0.069 & 0.068 & $\mathbf{0 . 0 6 9}$ & 0.070 & 0.056 \\
& $\%$ & $56 \%$ & $48 \%$ & $28 \%$ & $58 \%$ & $28 \%$ & $\mathbf{5 1 \%}$ & $63 \%$ & $43 \%$ \\
Skyhook & RMS ACC & 0.499 & 0.071 & 0.087 & 0.088 & 0.095 & $\mathbf{0 . 0 9 5}$ & 0.088 & 0.077 \\
& \% & $105 \%$ & $63 \%$ & $37 \%$ & $74 \%$ & $39 \%$ & $\mathbf{7 0 \%}$ & $79 \%$ & $58 \%$ \\
\hline
\end{tabular}

Table 4

Dimensionless RMS suspension travel

\begin{tabular}{|c|c|c|c|c|c|c|c|c|c|}
\hline \multicolumn{2}{|c|}{ Layout } & S3 & S4 & S5 & S6 & S7 & S8 & S9 & S10 \\
\hline \multirow{2}{*}{ Passive } & RMS & 4.240 & 5.508 & 16.503 & 5.936 & 16.089 & 5.781 & 4.434 & 5.393 \\
\hline & $\%$ & & $100 \%$ & $100 \%$ & $100 \%$ & $100 \%$ & $100 \%$ & $\%$ & $100 \%$ \\
\hline \multirow[t]{2}{*}{ Groundhook } & & 7.0 & 8.6 & 15. & & 15.2 & 6.416 & 6 & 8.601 \\
\hline & $\%$ & 167 & 15 & 94 & $107 c$ & 95 & $111 \%$ & $119 \%$ & $160 \%$ \\
\hline \multirow[t]{2}{*}{ Hybrid } & RMS & 3.668 & 3.987 & 3.757 & 3.659 & 3.795 & 3.709 & 3.619 & 3.986 \\
\hline & $\%$ & $87 c$ & $72 \%$ & $23 \%$ & $62 \%$ & $24 \%$ & $64 \%$ & $82 \%$ & $74 \%$ \\
\hline \multirow[t]{2}{*}{ Skyhook } & & 4.58 & 4.796 & 4.515 & 4.537 & 4.764 & 4.783 & 4.578 & 4.818 \\
\hline & $\%$ & $108 \%$ & $87 \%$ & $27 \%$ & $76 \%$ & $30 \%$ & $83 \%$ & $103 \%$ & $89 \%$ \\
\hline
\end{tabular}

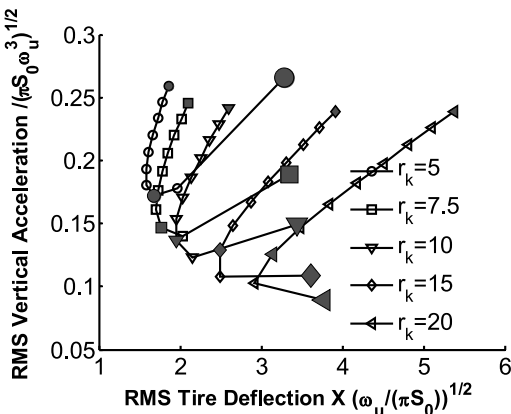

(a)

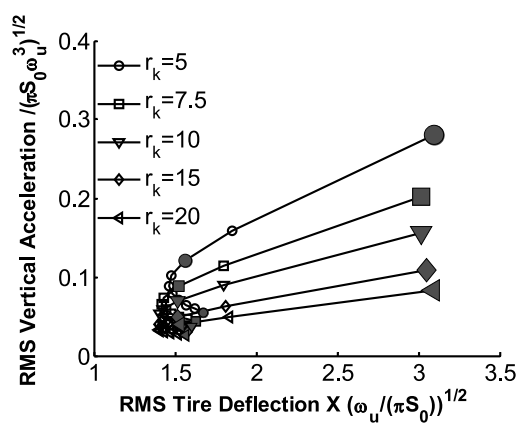

(c)

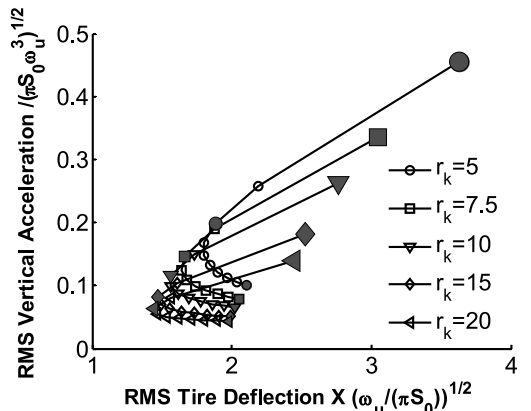

(b)

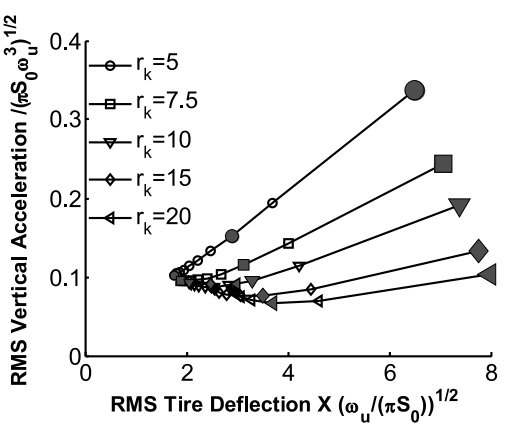

(d)

Fig. 5. Relationship between RMS acceleration and RMS tire deflection with layout $\mathrm{s} 8$ (effect of primary spring stiffness and damping): (a) Passive; (b) Groundhook; (c) Hybrid; (d) Skyhook.

the unsprung mass from base excitations. The Skyhook control focuses on the sprung mass, as damping increases, the sprung mass motion decreases. With the Skyhook, the RMS sprung mass vertical acceleration decreased 30\%, RMS suspension travel decreased $17 \%$ and RMS tire deflection increased $68 \%$. The Hybrid configuration has the best compromise between comfort and road holding quality: the RMS sprung mass vertical acceleration decreased 
Table 5

Dimensionless RMS tire deflection

\begin{tabular}{llcccccccc}
\hline \multicolumn{2}{c}{ Layout } & S3 & S4 & S5 & S6 & S7 & S8 & S9 & S10 \\
\hline Passive & RMS TDF & 4.444 & 1.667 & 2.141 & 1.623 & 2.376 & $\mathbf{1 . 9 5 3}$ & 1.599 & 1.893 \\
& $\%$ & $100 \%$ & $100 \%$ & $100 \%$ & $100 \%$ & $100 \%$ & $\mathbf{1 0 0 \%}$ & $100 \%$ & $100 \%$ \\
Groundhook & RMS TDF & 2.200 & 1.620 & 1.974 & 1.542 & 1.959 & $\mathbf{1 . 5 6 1}$ & 1.552 & 1.615 \\
& $\%$ & $49 \%$ & $97 \%$ & $92 \%$ & $95 \%$ & $82 \%$ & $\mathbf{8 0 \%}$ & $97 \%$ & $85 \%$ \\
Hybrid & RMS TDF & 2.639 & 1.517 & 1.503 & 1.504 & 1.512 & $\mathbf{1 . 5 1 4}$ & 1.507 & 1.510 \\
& $\%$ & $59 \%$ & $91 \%$ & $70 \%$ & $93 \%$ & $64 \%$ & $\mathbf{7 8 \%}$ & $94 \%$ & $80 \%$ \\
Skyhook & RMS TDF & 4.801 & 3.111 & 2.968 & 2.968 & 3.290 & $\mathbf{3 . 2 9 0}$ & 2.969 & 3.135 \\
& $\%$ & $108 \%$ & $187 \%$ & $139 \%$ & $183 \%$ & $138 \%$ & $\mathbf{1 6 8 \%}$ & $186 \%$ & $166 \%$ \\
\hline
\end{tabular}

Table 6

Dimensionless RMS tire deflection

\begin{tabular}{llcllllllc}
\hline \multicolumn{2}{c}{ Layout } & S3 & S4 & S5 & S6 & S7 & S8 & S9 & S10 \\
\hline Passive & RSM ACC & I & D & ID & ID & ID & ID & DI & D \\
& RSM SDF & I & D & ID & ID & ID & ID & DI & D \\
\multirow{5}{*}{ Groundhook } & RSM TDF & I & D & ID & ID & ID & ID & DI & D \\
& RSM ACC & I & D & ID & ID & ID & ID & DI & D \\
& RSM SDF & I & D & ID & ID & ID & ID & DI & D \\
& RSM TDF & I & D & ID & ID & ID & ID & DI & D \\
\hline
\end{tabular}

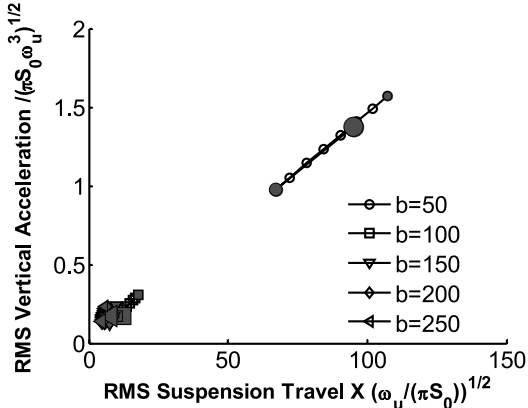

(a)

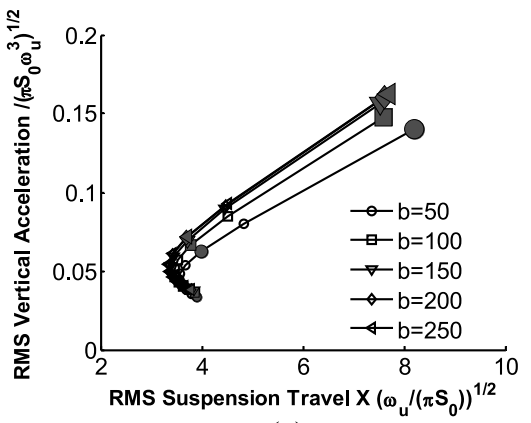

(c)

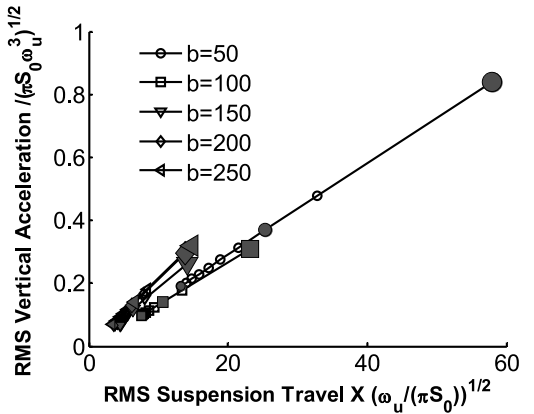

(b)

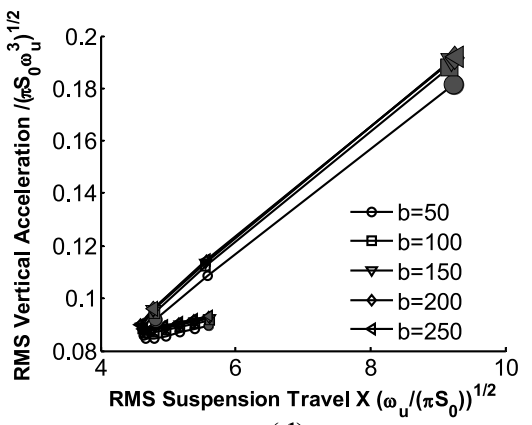

(d)

Fig. 6. Relationship between RMS acceleration and RMS suspension travel with layout s8 (effect of inertance and damping): (a) Passive; (b) Groundhook; (c) Hybrid; (d)Skyhook.

49\%, RMS suspension travel decreased $36 \%$ and RMS tire deflection decreased $22 \%$.

The performance comparison of all layouts is tabulated in Table 3 to Table 5. Damping ratio is fixed at 0.26 , $r_{k}$ is 10 and other parameters are from Table 2. Note that the RMS ACC is the dimensionless RMS of sprung mass vertical acceleration; RMS SDF is the dimensionless RMS of suspension deflection, and RMS TDF is the dimensionless RMS of tire deflection. The comparisons of these results show that for Layout s3 to Layout s10, using the Hybrid control method results much better performance than the passive suspension with same layout. 


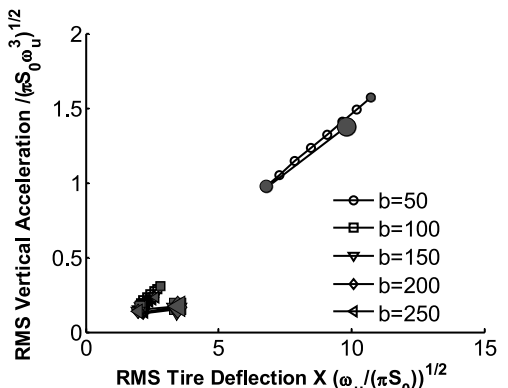

(a)

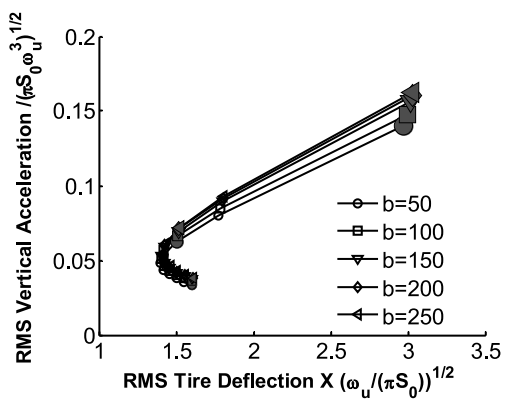

(c)

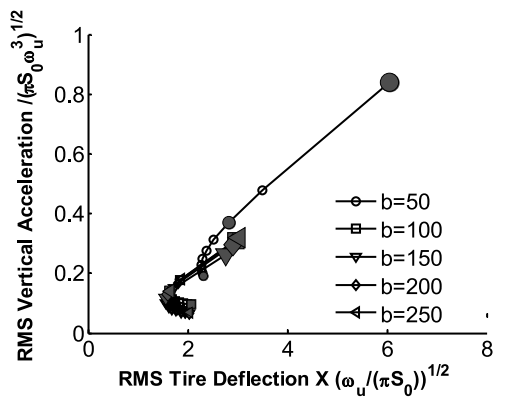

(b)

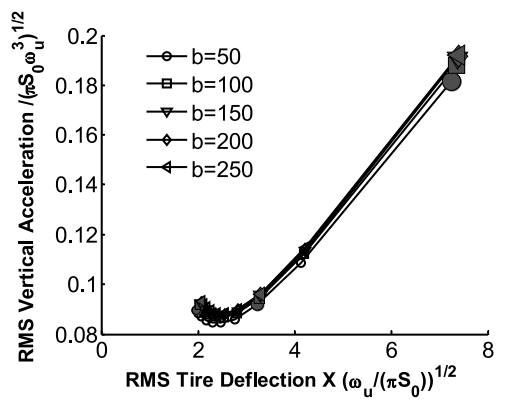

(d)

Fig. 7. Relationship between RMS acceleration and RMS tire deflection with layout s8 (effect of inertance and damping): (a) Passive; (b) Groundhook; (c) Hybrid; (d) Skyhook.

The performance of the semi-active suspension with Layout s4 to Layout s10 under the Hybrid control is nearly the same. The performance is not very sensitive with the primary spring stiffness when the Layout $\mathrm{s} 3$ is used.

\subsection{Effect of inertance and damping}

To investigate the effect of inertance, inertance, 'b', was changed from 50 to 250 and the damping was varied from $196 \mathrm{Ns} / \mathrm{m}$ to $3920 \mathrm{Ns} / \mathrm{m}$. ' $b$ ' is the equivalent mass of the inerter used throughout the whole analysis. The real mass is 1 to 2 kilogram [2]. The simulation with Layout s8 is shown in Figs 6 through 7.

The inertance has a large effect on the passive suspensions with inerters or semi-active suspensions with inerters under the Groundhook and is listed in Table 6. 'I' means the variable of interest will increase as the inertance increases; 'D' means it will decrease as the inertance increases; 'ID' means it will increase and then decrease and 'DI' is just the reverse. The turning point of Layout s6 or s8 is around 50 kilogram and for Layout s5, s7 or s9, it is around 100 kilogram. The optimization of the inertance should be done if the passive suspensions or semi-active suspensions under Groundhook with inerters. For the semi-active suspensions with inerters under the Skyhook or Hybrid control, the performance is nearly identical and robust with the change of the inertance. The Hybrid control made the best compromise between handling and ride performance. The semi-active suspension with an inerter is much more sensitive with the inertance when the inertance is small and as inertance increases, the performance doesn't increase significantly. The inertance is 150 kilogram in other studies in this research.

\subsection{Effect of centering spring $k_{1}$ and damping}

There are one or two centering springs in Layout s5 to Layout s9. The effect of these springs and damping are considered in this section. The dimensionless stiffness ratio of the centering spring $k_{1}$ is as follows:

$$
r_{k 1}=\frac{k_{1}}{k}
$$




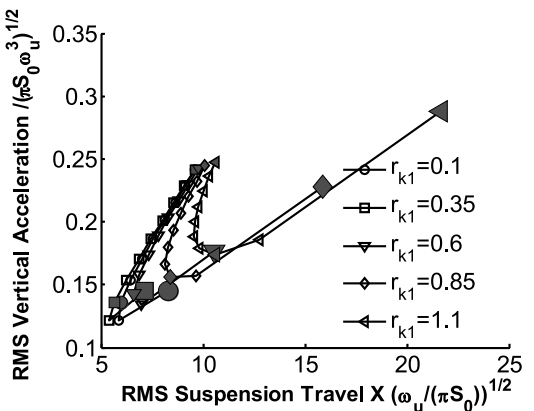

(a)

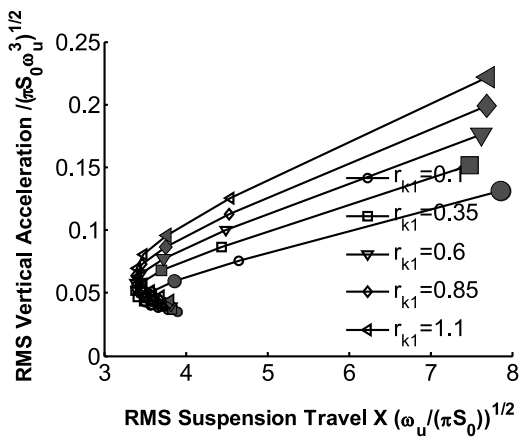

(c)

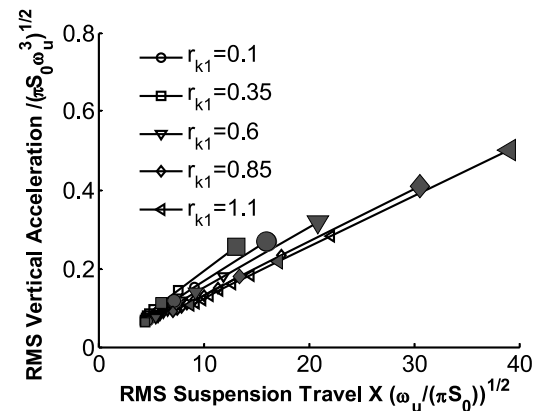

(b)

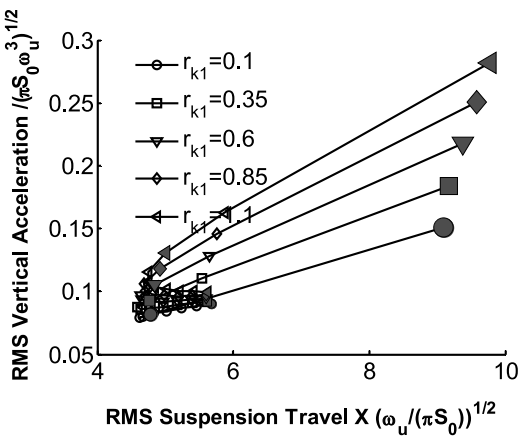

(d)

Fig. 8. Relationship between RMS acceleration and RMS suspension travel with layout s8 (effect of centering spring $k_{1}$ and damping): (a) Passive; (b) Groundhook; (c) Hybrid; (d) Skyhook.

where, $k_{1}$ is the centering spring static stiffness and $k$ is the primary spring stiffness. $r_{k 1}$ will be changed from 0.1 to 1.1 during simulation and damping has been varied from $196 \mathrm{Ns} / \mathrm{m}$ to $3920 \mathrm{Ns} / \mathrm{m}$. The performance of the semi-active suspensions with an inerter and passive suspensions with an inerter was compared and the result of Layout s8 is shown in Figs 8 and 9.

Layout s5 and Layout s7 have two identical centering springs. Layout s6 and Layout s8 have two centering springs of unequal stiffness. For Layout s5 and Layout s7, increasing the centering springs' stiffness, results the suspension's performance to decrease first and then increase. For Layout s6, s8, and s9, the performance of the suspension will increase first then turn to worse with the increasing of centering spring's stiffness. As the simulations show, a suspension will have a much better performance when the dimensionless stiffness of centering spring is around 0.4 under Hybrid control, which is nearly the slope of the result shown in Fig. 6 of Smith and Wang's research [12]. It also shows that the dimensionless stiffness of the centering spring of Layout s5 should be smaller than the one of Layout s6.

\subsection{Effect of centering spring $k_{2}$ and damping}

Layout s6 and Layout s8 have two unequal centering springs. One is $k_{1}$ and the other is $k_{2}$. The sensitivity of $k_{2}$ is investigated in this section. The dimensionless stiffness ratio of the centering spring $k_{2}$ is,

$$
r_{k 2}=\frac{k_{2}}{k}
$$

where, $k_{2}$ is the centering spring static stiffness and $k$ is the primary spring stiffness. $r_{k 2}$ is changed from 0.03 to 0.15 during the simulation and damping has been varied from $196 \mathrm{Ns} / \mathrm{m}$ to $3920 \mathrm{Ns} / \mathrm{m}$. The comparison of the semi-active suspension with Layout s8 and the passive suspension with Layout s8 is listed in Figs 10 and 11. 


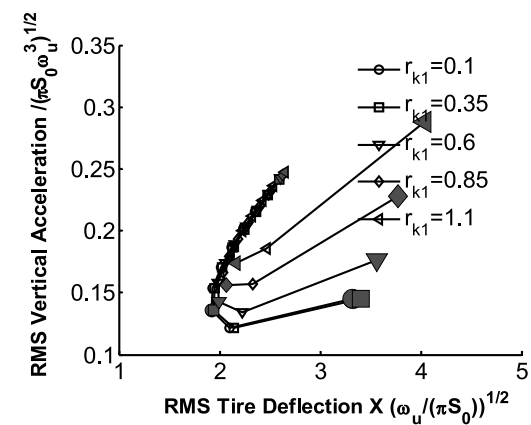

(a)

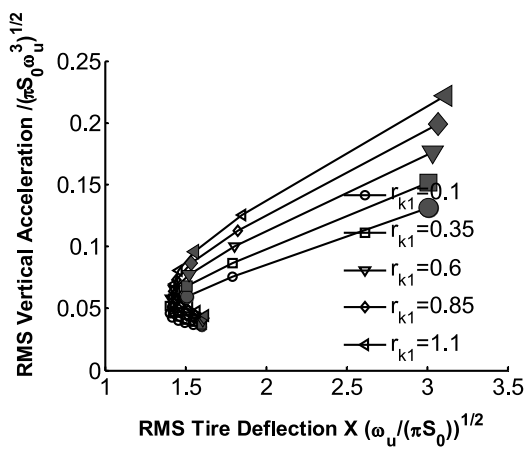

(c)

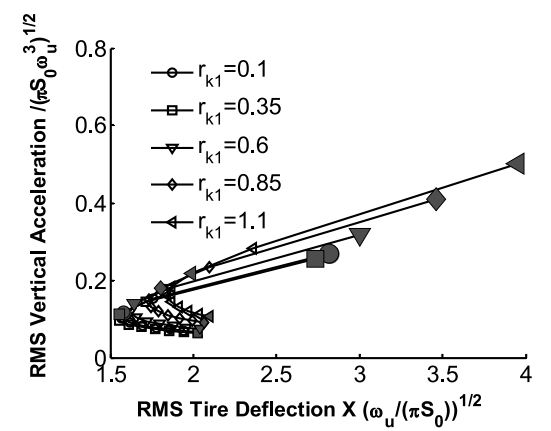

(b)

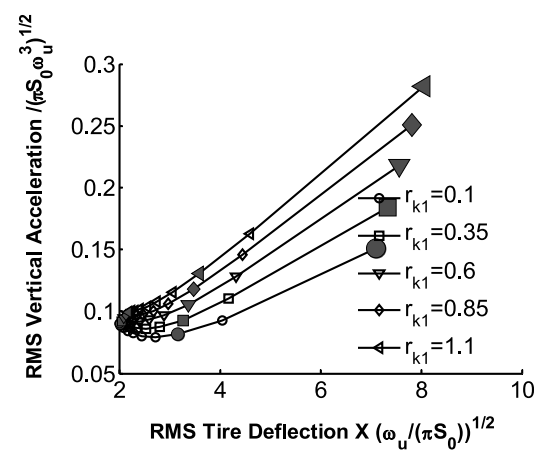

(d)

Fig. 9. Relationship between RMS acceleration and RMS tire deflection with layout s8 (effect of centering spring $k_{1}$ and damping): (a) Passive; (b) Groundhook; (c) Hybrid; (d) Skyhook.

The semi-active suspension with an inerter with Layout s6 and Layout s8 has the best performance with the Hybrid control and it is not sensitive with the change of the stiffness of centering spring paralleled with the inerter and dimensionless stiffness of centering spring. $r_{k 2}$ is set to 0.15 in other studies.

\subsection{Effect of relaxation spring $k_{b}$ and damping}

There is a relaxation spring in Layout s7, s8, and s10, which it is studied in this section. The dimensionless relaxation spring stiffness ratio of the relaxation spring $k_{b}$ is,

$$
r_{k b}=\frac{k_{b}}{k}
$$

$k_{b}$ is varied from 2 to 12 during the simulation and the damping has been varied from $196 \mathrm{Ns} / \mathrm{m}$ to $3920 \mathrm{Ns} / \mathrm{m}$. A comparison of the semi-active suspension and the passive suspension both with Layout s8 is shown in Figs 12 and 13.

For Layout s7, Layout s8, and Layout s10, the performance of semi-active suspension with an inerter is much better than the passive one, especially with the Hybrid control. The semi-active suspension with an inerter is not sensitive to the change of relaxing spring stiffness. For the passive suspension with Layout s8, the relaxing spring doesn't significantly help in improving the vertical acceleration of the sprung mass. The tire deflection will decrease when increasing the dimensionless relaxation spring stiffness ratio and it is set to 4 in other studies of this paper because the performance of the passive suspension does not significantly change when the $r_{k b}$ is greater than 4 . Figure 14 is the frequency response of the sprung mass acceleration, the suspension deflection, and the tire deflection with the different relaxing springs.

The tire deflection frequency response shows that the value of the tire deflection will decrease with the increase in the static stiffness of the relaxing spring at the unsprung mass natural frequency. The relaxing spring maintains a significant control over tire deflection at high-frequency small-amplitude inputs. 


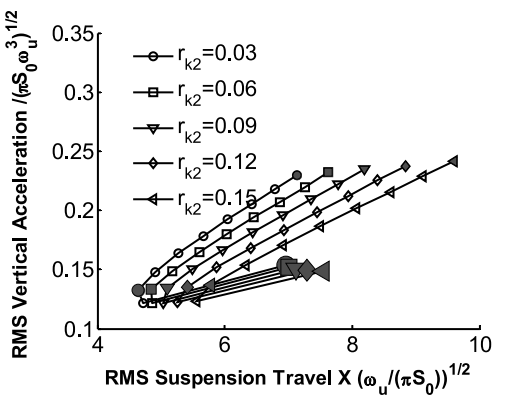

(a)

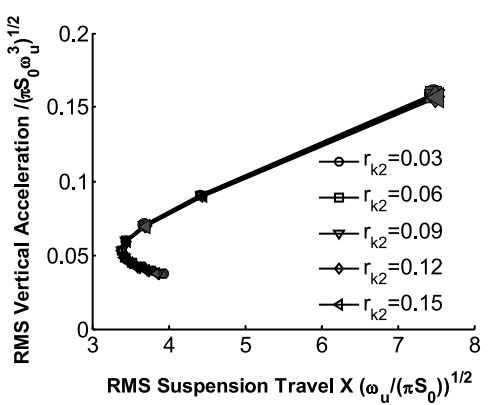

(c)

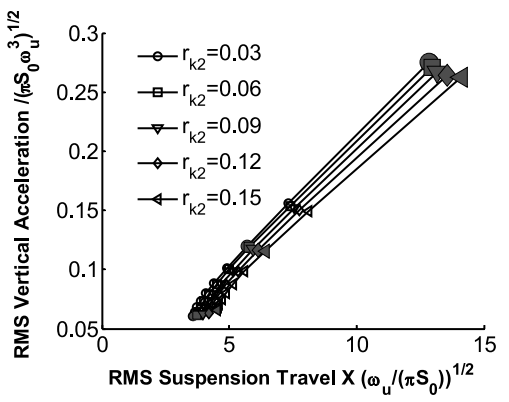

(b)

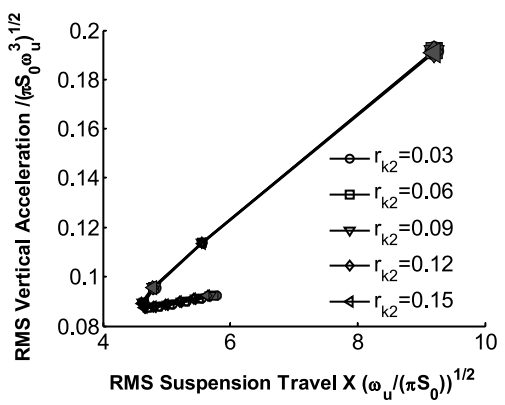

(d)

Fig. 10. Relationship between RMS acceleration and RMS suspension travel with layout s8 (effect of centering spring $k_{2}$ and damping): (a) Passive; (b) Groundhook; (c) Hybrid; (d) Skyhook.

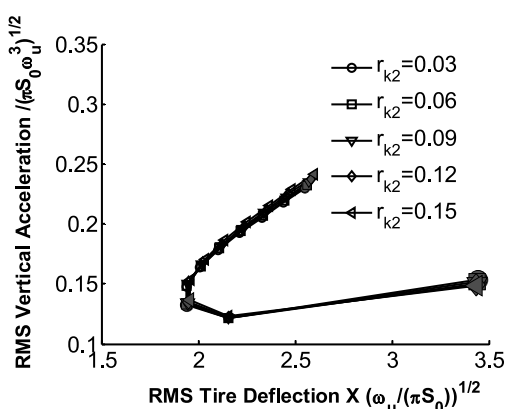

(a)

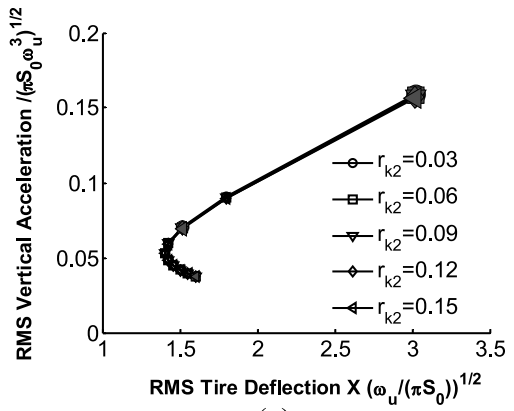

(c)

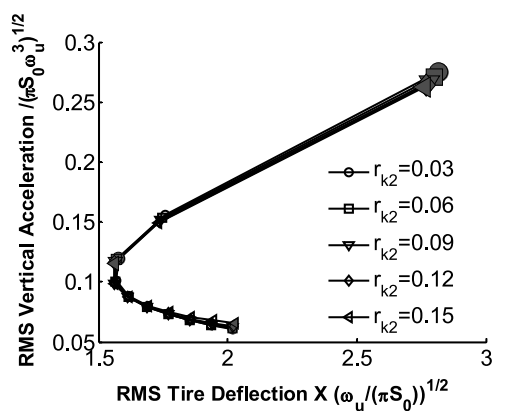

(b)

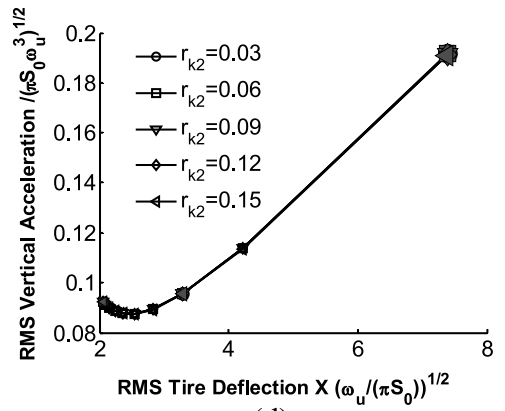

(d)

Fig. 11. Relationship between RMS acceleration and RMS tire deflection with layout $\mathrm{s} 8$ (effect of centering spring $k_{2}$ and damping): (a) Passive; (b) Groundhook; (c) Hybrid; (d) Skyhook. 


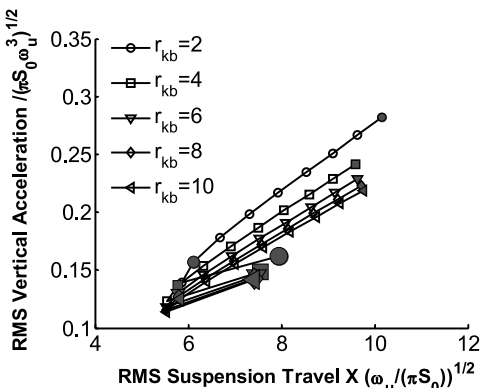

(a)

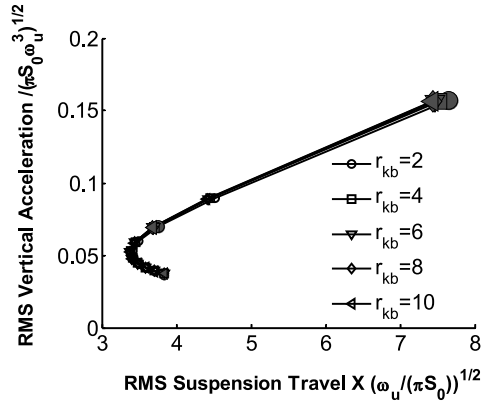

(c)

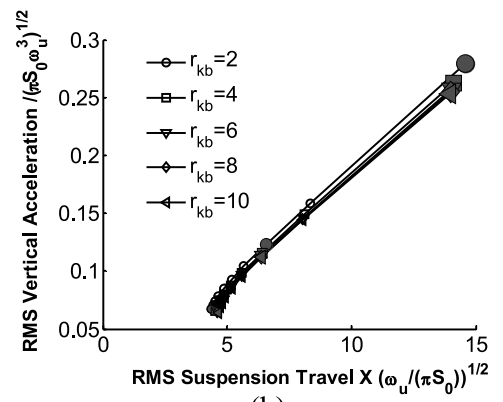

(b)

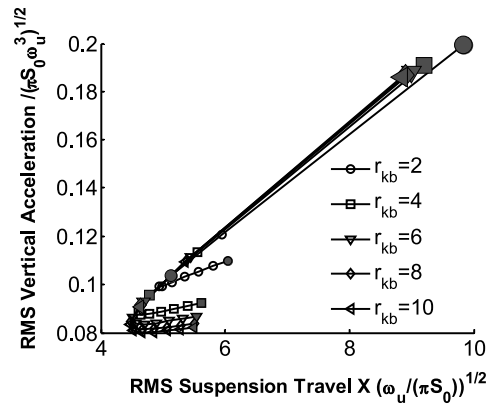

(d)

Fig. 12. Relationship between RMS acceleration and RMS suspension travel with layout $\mathrm{s} 8$ (effect of centering spring $k_{b}$ and damping): (a) Passive; (b) Groundhook; (c) Hybrid; (d) Skyhook.

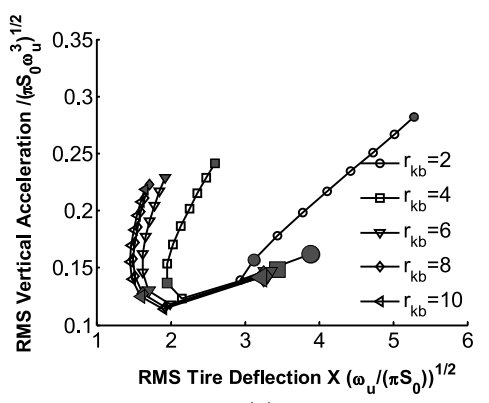

(a)

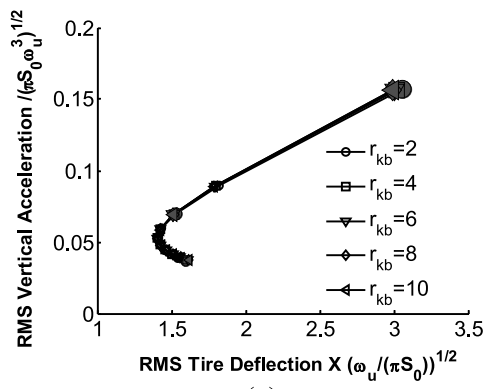

(c)

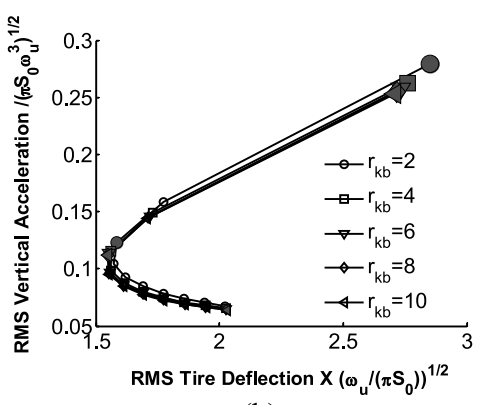

(b)

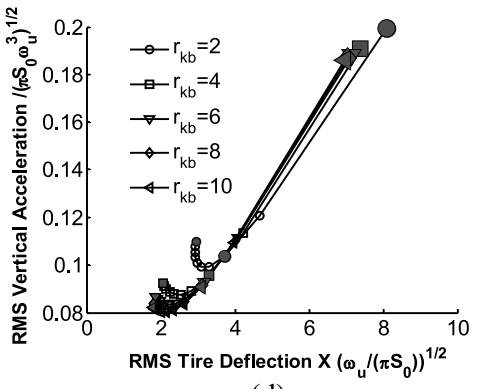

(d)

Fig. 13. Relationship between RMS acceleration and RMS tire deflection with layout $\mathrm{s} 8$ (effect of centering spring $k_{b}$ and damping): (a) Passive; (b) Groundhook; (c) Hybrid; (d) Skyhook. 


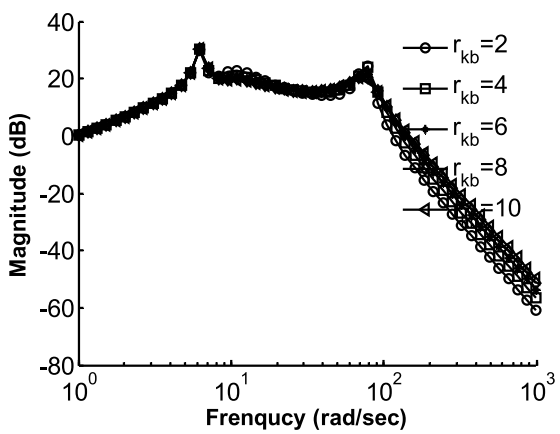

(a)

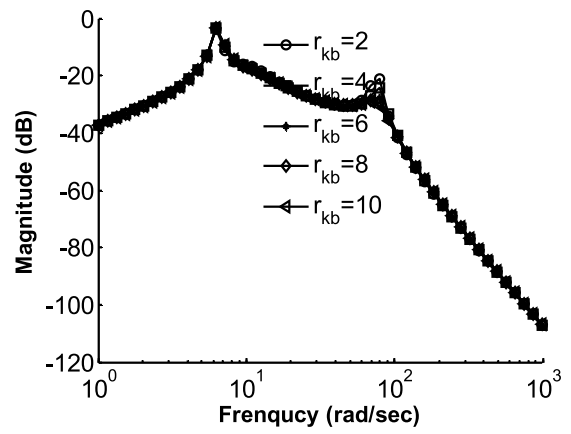

(b)

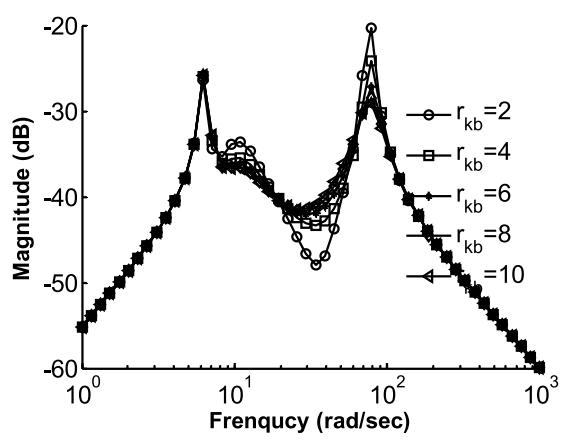

(c)

Fig. 14. Frequency response with layout s8: (a): Sprung mass acceleration response; (b): Suspension deflection response; (c): Tire deflection response.

\section{Conclusions}

The performance of eight different passive and semi-active suspensions with inerters were analyzed and compared with each other in this paper. Sensitivity analysis was applied to the development of a high performance semi-active suspension with an inerter. Some of the simulation results are as follows:

1. The semi-active suspensions from Layout $s 3$ to Layout $s 10$ have much better performance than the passive suspension with same layout strut, especially with the Hybrid control method. For Layout s8, the Hybrid configuration has the best compromise between comfort and road holding quality: the RMS sprung mass vertical acceleration decreased 49\%, RMS suspension travel decreased $36 \%$ and RMS tire deflection decreased $22 \%$ over the passive case. A semi-active suspension performs its best under the Skyhook or Groundhook control depending on the desired performance. Also, the semi-active suspension with an inerter is more robust with the parameters changing and is not sensitive to the change of the stiffness of centering spring paralleled with the inerter and the relaxing spring. The centering spring $k_{1}$ in Layout $\mathrm{s} 5$ and Layout $\mathrm{s} 7$ should be softer than the ones in Layouts6 and Layout $\mathrm{s} 8$. The performance is not very sensitive to the primary spring stiffness when the Layout $\mathrm{s} 3$ is used. It also shows that a stiffer sprung will bring a better performance.

2. For semi-active suspensions with inerters under Skyhook or Hybrid control, the performance is nearly the same and it is robust with inertance change. The semi-active suspension with an inerter is much more sensitive to inertance when the mass is small. As inertance gets higher, the performance doesn't improve much.

3. The tire deflection frequency response shows that the value of the tire deflection will decrease with an increase of the static stiffness of the relaxing spring at the unsprung mass natural frequency. The relaxing spring maintains a significant control over tire deflection at high-frequency small-amplitude inputs. 


\section{References}

[1] J.K. Hedrick and T. Butsuen, Invariant properties of automotive suspensions, Proc Inst Mech Eng 204 (1990), $21-27$.

[2] M.C. Smith, Synthesis of mechanical networks: the inerter, IEEE Transaction on Automatic Control 47 (2002), 1648-1662.

[3] F.C. Wang, C.W. Chen, M.K. Liao and M.F. Hong, Performance Analyses of Building Suspension Control with Inerters, 46th IEEE Conference on Decision and Control New Orleans, LA, USA, 2007, pp. 3786-3791.

[4] F.C. Wang, C.H. Yu, M.L. Chang and M.S. Hsu, The performance improvements of train suspension systems with inerters, 45th IEEE Conference on Decision and Control, San Diego, USA, 2006, pp. 1472-1477.

[5] C. Papageorgiou, O.G. Lockwood, N.E. Houghton and M.C. Smith, Experimental Testing and Modelling of a Passive Mechanical Steering Compensator for High-Performance Motorcycles, European Control Conference Kos, Greece, 2007, pp. 3592-3599.

[6] M.C. Smith, Force-Controlling Mechanical Device, U.S., Patent, 7316303B2, 2008.

[7] F.C. Wang, M.S. Hsu, W.J. Su and T.C. Lin, Screw Type Inerter Mechanism, U.S., Patent, 200910108510A1, 2009.

[8] F.C. Wang and T.C. Lin, Hydraulic Inerter Mechanism, U.S., Patent, 200910139225 A1, 2009.

[9] C. Papageorgiou, N.E. Houghton and M.C. Smith, Experimental Testing and Analysis of Inerter Devices, The Dynamics System, Measurement, and Control Division of ASME 131(011001) (2009), pp. 1-11.

[10] C. Papageorgiou and M.C. Smith, Positive real synthesis using matrix inequalities for mechanical networks:Application to vehicle suspension, IEEE Trans Control Syst Technol 14(3) (2006), 423-443.

[11] M.Z.Q. Chen, C. Papageorgiou, F. Scheibe, F.C. Wang and M.C. Smith, The Missing Mechanical Circuit Element, IEEE Circuits and Systems Magazine First Quarter (2009), 10-26.

[12] M.C. Smith and F.C. Wang, Performance benefits in passive vehicle suspensions employing inerters, Veh Syst Dyn 42(4) (2004), $235-257$.

[13] F.C. Wang and W.J. Su, Inerter Nonlinearities and the Impact on Suspension Control, American Control Conference, Washington, USA, 2008, pp. 3245-3250.

[14] F.C. Wang and W.J. Su, Impact of inerter nonlinearities on vehicle suspension control, Veh Syst Dyn 46(7) (2008), 575-595.

[15] F.C. Wang and H.A. Chan, Mechatronic Suspension Design and Its Applications to Vehicle Suspension Control, 47th IEEE Conference on Decision and Control Cancun, Mexico, 2008, pp. 3769-3774.

[16] M. Ahmadian, A Hybrid Semiactive Control for Secondary Suspension Applications, Proceedings of the Sixth ASME Symposium on Advanced Automotive Technologies, 1997 ASME International Congress and Exposition, 1997.

[17] R.M. Chalasani, Ride Performance Potential of Active Suspension Systems - Part I: Simplified Analysis Based on a Quarter-Car Model, ASME Symposium on Simulation and Control of Ground Vehicles and Transportation Systems AMD-vol. 80(DSC-vol. 2) (1986), $187-204$.

[18] E.D. Blanchard, On the Control Aspects of Semiactive Suspension for Automobile Applications, M.S. Thesis, Virginia Polytechnic Institute and State University, Blacksburg, VA, 2003. 

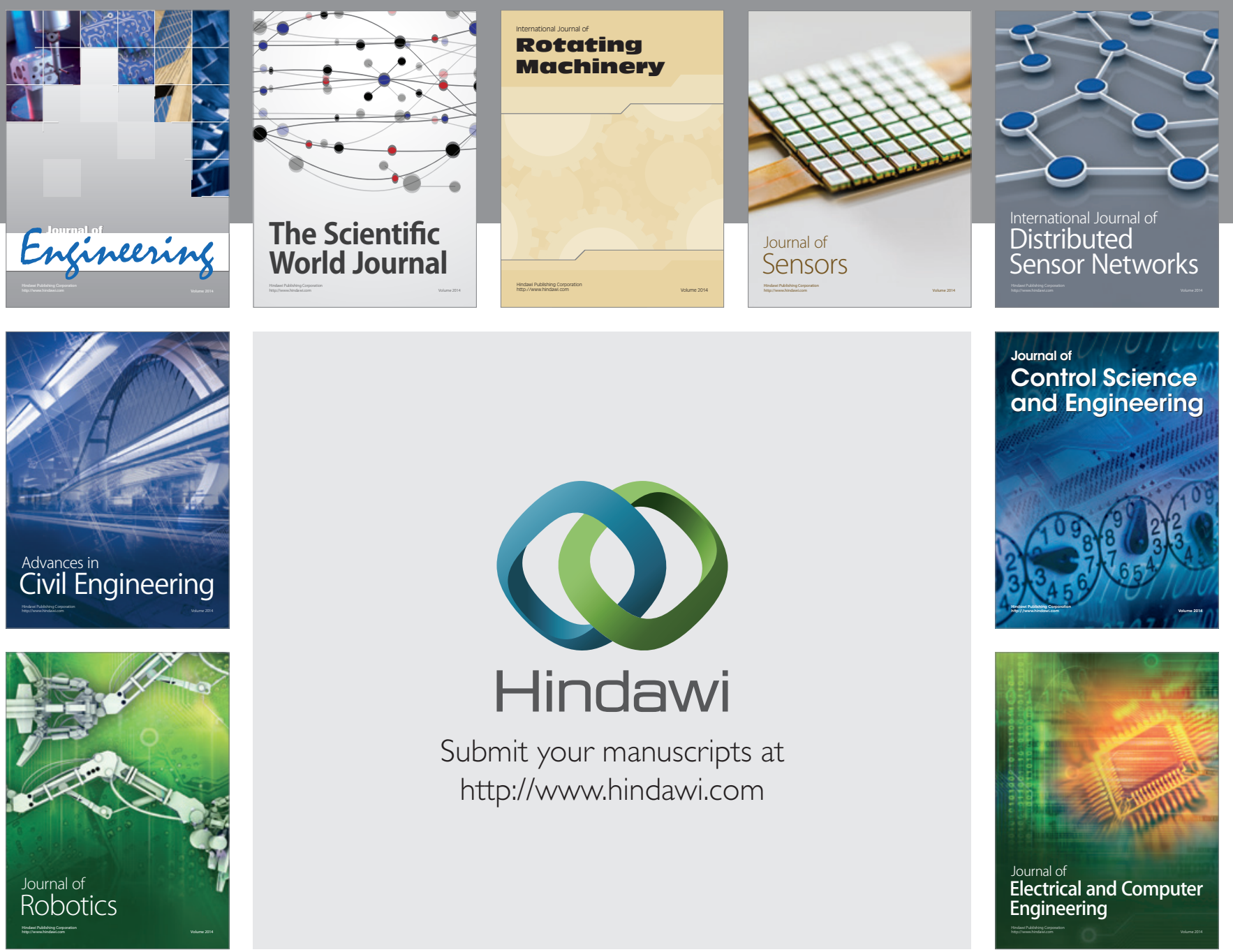

Submit your manuscripts at

http://www.hindawi.com
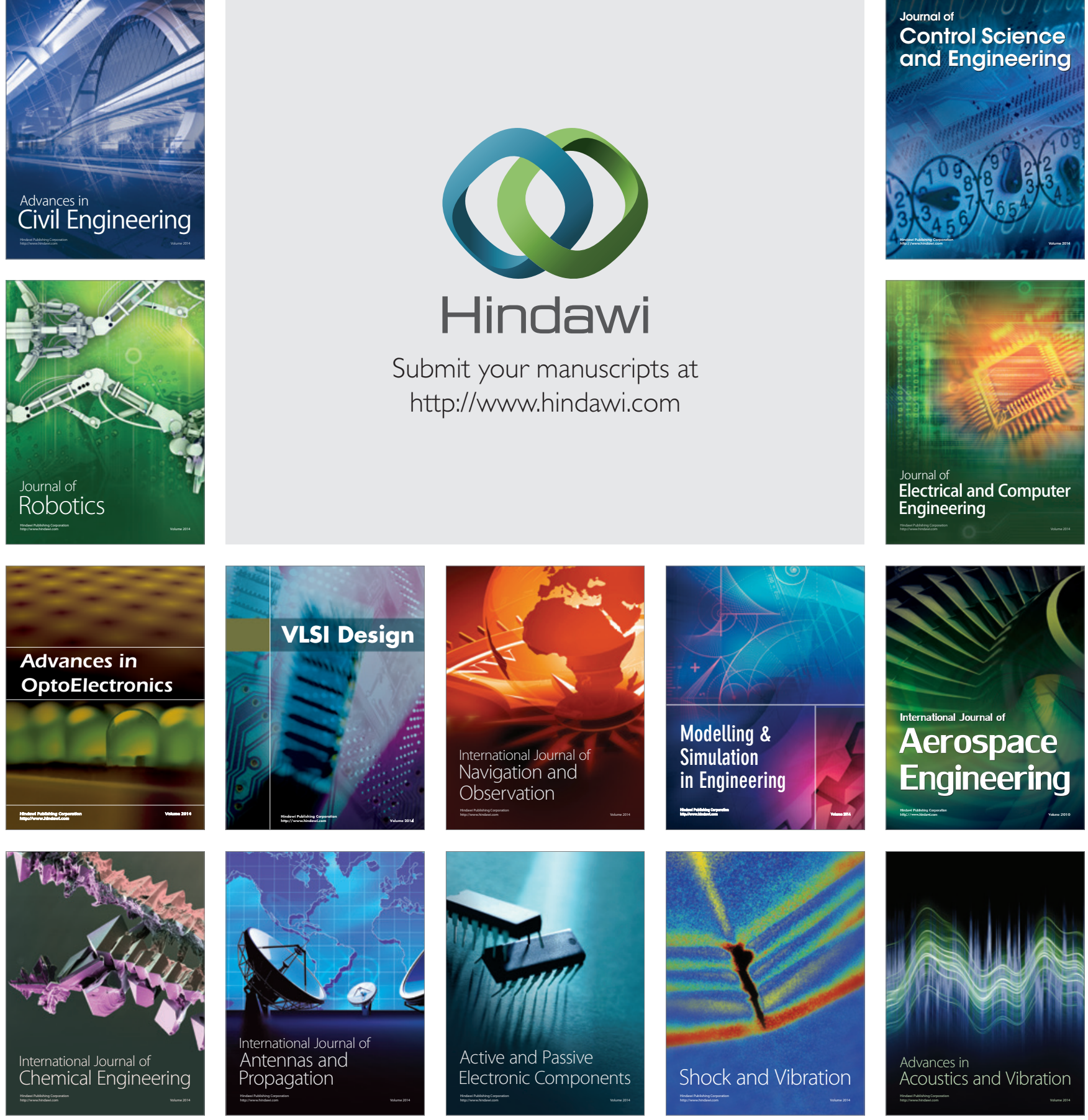